https://doi.org/10.35336/VA-2021-1-5-13

ПРИМЕНЕНИЕ СТЕРЕОТАКСИЧЕСКОЙ РАДИОХИРУРГИИ В ЭКСПЕРИМЕНТЕ НА КРУПНЫХ ЖИВОТНЫХ ДЛЯ ПРОВЕДЕНИЯ НЕИНВАЗИВНЫХ ВМЕШАТЕЛЬСТВ В АРИТМОЛОГИИ

В.А.Васковский ${ }^{1}$, И.А.Таймасова ${ }^{1}$, Д.В.Калинин ${ }^{1}$, Н.А.Антипина ${ }^{2}$, А.А.Николаева ${ }^{2}$, Г.Ю.Смирнов ${ }^{2}$ А.В.Голанов ${ }^{2}$, А.А.Потапов ${ }^{2}$, А.Ш.Ревишвили ${ }^{1}$

${ }^{1}$ Федеральное государственное бюджетное учреждение «Национальный медицинский исследовательский центр хирургии имени А.В.Вииневского» Министерства здравоохранения Российской Федерации, Москва; ${ }^{2}$ Федеральное государственное автономное учреждение «Национальный медицинский исследовательский центр нейрохирургии имени академика Н.Н.Бурденко» Министерства здравоохранения Российской Федерации, Москва

Целью экспериментального исследования являлось изучение эффектов стереотаксической радиоаблации различной дозы на миокард предсердий, желудочков и атриовентрикулярное (AВ) соединение в отдаленном периоде (до 6 месяцев); а также оценка коллатерального повреждения при радиоаблации.

Методы исследования. Исследование выполнено на 4 домашних свиньях. Возраст животных составил 10 -

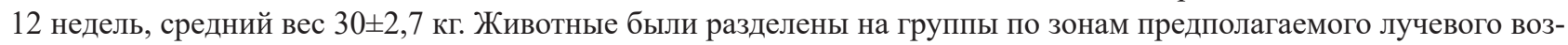
действия: 1 животное - АВ узел (доза 35 Гр), 2 животное - АВ-узел и верхушка левого желудочка (Лж) (доза 40/35 Гр, соответственно), 3-е - устья легочных вен (ЛВ) и левое предсердие (доза 30 Гр), 4-е - АВ узел и свободная стенка ЛЖ (доза 45/40 Гр, соответственно). Под внутривенной седацией с аппаратным контролем гемодинамики выполнялась компьютерная томография сердца с контрастированием для оценки степени смещения камер сердца за один дыхательный и сердечный циклы и оценки анатомии камер сердца и смежных органов. Выделение зон воздействия проводилось в 3-х проекциях: аксиальной, фронтальной и сагиттальной. Для электрофизиологического (ЭФ) контроля животным имплантировались петлевые регистраторы. Среднее время облучения составило $11 \pm 7$ минут. Срок отдаленного наблюдения составлял 6 месяцев с последующим проведением морфологического исследования аутопсийного материала.

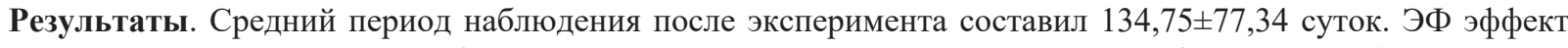
был достигнут при воздействии в область АВ-узла в виде развития преходящей АВ-блокады 3 ст. (2 животное 40 Гр на 108 сутки наблюдения) и полной АВ-блокады с асистолией (4 животное 45 Гр на 21 сутки наблюдения). При воздействии на ЛВ и ЛЖ нарушений ритма сердца не зафиксировано. При макро- и микроскопическом исследовании отмечались заметные изменения в области воздействия, имеющие четкие, но не ровные границы зоны повреждения, не выходящие за пределы запланированных (конформное воздействие с высокой степенью прецизионности). Отмечался трансмуральный характер изменений: массивные поля фиброзной ткани различной степени зрелости (с преобладанием субэпикардиального повреждения) с очаговыми кровоизлияниями различной давности и грануляциями, окруженными кардиомиоцитами с коагуляцией и вакуолизацией цитоплазмы.

Заключение. Применение данной технологии для лечения тахиаритмий имеет высокие перспективы в современной аритмологии в качестве альтернативного метода аблации

Ключевые слова: стереотаксическая радиоаблация; желудочковые тахикардии; неинвазивная аблация.

Конфликт интересов: не заявляется

Рукопись получена: 06.12.2020 Исправленная версия получена: 09.02.2021 Принята к публикации: 15.02 .2021 Ответственный за переписку: Валентин Анатольевич Васковский, E-mail: vvaskov03@mail.ru

Для цитирования: Васковский ВА, Таймасова ИА, Калинин ДВ, Антипина НА, Николаева АА, Смирнов ГЮ, Голанов АВ, Потапов АА, Ревишвили АШ. Применение стереотаксической радиохирургии в эксперименте на крупных животных для проведения неинвазивных вмешательств в аритмологии. Вестник аритмологии. 2021;28(1): 5-13. https://doi.org/10.35336/VA-2021-1-5-13.

\title{
EXPERIMENTAL USE OF STEREOTACTIC RADIOSURGERY FOR NON-INVASIVE INTERVENTIONS IN ARRHYTHMOLOGY
}

V.A.Vaskovskiy ${ }^{1}$, I.A.Taymasova ${ }^{1}$, D.V.Kalinin ${ }^{1}$, N.A.Antipina², A.A.Nikolaeva ${ }^{2}$, G.Y.Smirnov ${ }^{2}$, A.V.Golanov ${ }^{2}$, A.A.Potapov ${ }^{2}$, A.Sh.Revishvili ${ }^{1}$

${ }^{1}$ A.V. Vishnevskiy National Medical Research Center of Surgery, Moscow, Russia; ${ }^{2}$ N.N. Burdenko National Medical Research Center of Neurosurgery, Moscow, Russia

Purpose. The aim of the experimental study was to study the effects of stereotaxic radioablation of various doses on the myocardium of the atria, ventricles and atrioventricular (AV) node in the long term (up to 6 months); as well as assessment of collateral damage during radioablation. 
Material and methods. The research was carried out on 4 domestic pigs. The animals were 10-12 weeks old, the average weight was $30 \pm 2.7 \mathrm{~kg}$. Linear accelerator «TrueBeam», Varian was used for the experiment. Animals were divided into groups according to the zones of planned radiation exposure: 1st animal - AV node (dose 35 Gy), 2nd animal - AV node and the apex of the left ventricle (LV) (dose 40/35 Gy, respectively), 3rd animal - pulmonary veins (PV) and left atrium (dose $30 \mathrm{~Gy}$ ), 4th - AV node and free wall of the LV (dose 45/40 Gy). Under intravenous sedation with hemodynamic monitoring, contrast-based CT of the heart was performed to assess the degree of displacement of the heart chambers in one respiratory and cardiac cycle and to assess the anatomy of the chambers of the heart and adjacent organs. The allocation and the contouring of the target zones were carried out in 3 projections: axial, frontal and sagittal. For electrophysiological control, loop recorders were implanted in each animal. The average exposure time was $11 \pm 7$ minutes. The long-term follow-up period was 6 months, followed by morphological examination of autopsy material.

Results. The average follow-up period after the experiment was $134.75 \pm 77.34$ days. The electrophysiological effect of the ablation was achieved in cases of complete AV-block development. This effect was developed in 2 out of 3 animals, whose AV-node was exposed: 2nd animal - 40 Gy on $108^{\text {th }}$ day of observation and 4th animal - 45 Gy on $21^{\text {st }}$ day of observation. No cardiac arrhythmias were recorded in all cases. The results of macro- and microscopic examination showed significant changes in the target zones. These areas had precise but uneven damage boundaries, which were within the planned ones (conformal exposure with a high degree of precision). The transmural nature of the changes was noted as well. Massive fields of fibrous tissue of various degrees of maturity (with a predominance of subepicardial localization) with focal hemorrhages of various ages and granulations were detected, which were surrounded by cardiomyocytes with coagulated and vacuolated cytoplasm.

Conclusion. The use of non-invasive stereotactic treatment of tachyarrhythmias has high prospects in modern arrhythmology as an alternative ablation method.

Key words: stereotactic radioablation; ventricular tachycardia; noninvasive ablation

Conflict of Interests: nothing to declare

Received: 06.12.2020 Revision received: 09.02.2021 Accepted: 15.02.2021

Corresponding author: Valentin Vaskovskiy, E-mail: vvaskov03@mail.ru

For citation: Vaskovskiy VA, Taymasova IA, Kalinin DV, Antipina NA, Nikolaeva AA, Smirnov GY, Golanov AV, Potapov AA, Revishvili ASh. Experimental use of stereotactic radiosurgery for non-invasive interventions in arrhythmology. Journal of Arrhythmology. 2021;28(1): 5-13. https://doi.org/10.35336/VA-2021-1-5-13.

Распространенность тахиаритмий в популяции определяет развитие методик для лечения данной патологии. Новые подходы в лечении, направленные на повышение эффективности и безопасности уже известных методик лечения являются приоритетным направлением развития современной аритмологии.

Катетерные методы аблации завоевали прочное место в рекомендациях по лечению тахиаритмий, в том числе в качестве первой линии лечения. Однако у катетерной радиочастотной и криоаблации существует ряд недостатков: инвазивность, недостаточная глубина повреждения миокарда, риск тромбообразования внутри полостей сердца и перфорации сердца [1-6].

В последние десятилетия стереотаксическое облучение патологических очагов различной природы с помощью установок со множественными источниками $\mathrm{Co}^{60}$, ускорителей электронов и тяжелых заряженных частиц становится все более распространенным методом лучевой терапии в онкологии (преимущественно в приложении к новообразованиям головного мозга). В стереотаксической лучевой терапии и радиохирургии используются современные технологии, которые позволяют подводить излучение к «мишени» с большого количества направлений, с высокой степенью прецизионности и селективности. Это обеспечивает конформное (совпадающее по объему с объемом патологического очага) облучение, максимально снижая воздействие на окружающие «здоровые» ткани и минимизируя острые и отсроченные лучевые осложнения
[7]. Известными специалистами - профессорами Jean Regis и John Adler, для обоснования функциональных радиохирургических вмешательств при гиперкинезах и болевых синдромах была выдвинута концепция нейромодуляции, под которой подразумевается, что подведение высоких доз ионизируюшей энергии приводит не просто к формированию очага деструкции, но и к модуляции той или иной функции. Неинвазивное стереотаксическое лечение с помощью линейных ускорителей электронов может считаться многообещающей альтернативой катетерной аблации у пациентов с тахиаритмиями, что было продемонстрировано в ряде работ по экспериментальному и клиническому применению данной технологии [8].

Высокая эффективность и безопасность стереотаксической лучевой терапии с использованием ускорителей электронов и протонов, появление систем навигации и совершенствование методик планирования и расчета дозовых распределений, в том числе с учетом движения различных анатомических структур, позволило применять данный метод лечения при болезнях непрерывно движущихся органов, например, заболеваниях дыхательной и сердечной систем. Схожесть задач онкологов и аритмологов (создание стойкого и точного повреждения ткани органа с формированием в последующем фиброза и, как следствие, «блока проведения»), позволила начать экспериментальные и доклинические исследования по применению этой технологии для лечения тахиаритмий. 
В зарубежных экспериментальных исследованиях на животных показана высокая эффективность применения стереотаксической радиоаблации для создания устойчивого функционального повреждения тканей сердца. Существует ряд публикаций о клиническом применении стереотаксической аблации для лечения тахиаритмий $[9,10]$. Однако в этих работах не описаны методические аспекты процедуры, позволяющие воспроизвести результаты.

Целью нашего экспериментального исследования являлось изучение эффектов стереотаксической радиоаблации различной дозы на миокард предсердий, желудочков и артриовентрикулярное (АВ) соединение в отдаленном периоде (до 6 месяцев); а также оценка коллатерального повреждения при радиоаблации.

\section{МАТЕРИАЛ И МЕТОДЫ ИССЛЕДОВАНИЯ}

Исследование по применению стереотаксической радиоаблации сердца было проведено сотрудниками НМИЦ хирургии им. А.В.Вишневского совместно с НМИЦ нейрохирургии им. Н.Н.Бурденко МЗ РФ.

Исследование выполнено на 4 домашних свиньях (метисы Sus scrofa domesticus - по 2 особи мужского и женского пола). Период проведения экспериментальной части исследования: декабрь 2019 - февраль 2020 года. Возраст животных составил 10-12 недель, средний вес $30 \pm 2,7$ кг. Животные были разделены на группы по зонам предполагаемого лучевого воздействия: 1 животное - АВ узел (доза 35 Гр), 2 животное - АВ-узел и верхушка левого желудочка (ЛЖ) (доза 40/35 Гр, соответственно), 3-е устья легочных вен (ЛВ) и левое предсердие (ЛП) (доза 30 Гр), 4-е - АВ узел и свободная стенка ЛЖ (доза 45/40 Гр, соответственно). Дозы воздействия были основаны на результатах более ранних исследований других научных групп $[9,10]$. Исследование было проведено на линейном ускорителе TrueBeam STx (Varian, США).
Животные седатировались (внутривенно кетамин 4,4 мг/кг, золетил 2 мг/кг), находясь на самостоятельном дыхании с подачей увлаженного кислорода, проводился контроль параметров гемодинамики (АД, ЧСС, $\mathrm{SaO}_{2}$, число дыхательные движений). Далее проводилась иммобилизация животного на специальном вакуумном матрасе. Первым этапом выполнялась мультиспиральная компьютерная томография сердца (МСКТ) (рис. 1). Для оценки степени смещения камер сердца за один дыхательный и сердечный циклы выполнялась «нативная» серия КТ (для проведения разметки области интереса). Для оценки анатомии камер сердца и смежных органов выполнялась серия КТ с контрастным усилением. Вторым этапом выполнялось выделение («оконтуривание») зон воздействия с использованием изображения МСКТ в 3-х проекциях: аксиальной, фронтальной и сагиттальной. Для этого использовалось программное обеспечение для дозиметрического планирования облучения Eclipse Treatment Planning System (Varian, США). Выбранная зона («мишень») выделялась на каждой серии томограмм с шагом 1,25-1,3 мм. Далее, от контуров «мишени» выполнялся отступ до 5 мм для расширения зоны облучения и включения в нее всех возможных положений «мишени» в пространстве с учетом ее движения, связанного с дыхательным и сердечным циклами (рис. 2-5). Выделенная зона оценивалась по следующим параметрам: первоначальный объем (GTV-gross target volume - объем «мишени», видимый по изображениям), конечный объем с учетом отступа (PTV-planning target volume - облучаемый объем), близость важных анатомических структур к зоне интереса (пищевод, ткань легкого) (см. рис. 1).

Третьим этапом выполнялось непосредственно лучевое воздействие. Характеристики выбранных зон и параметров воздействия представлены в табл. 1. Четвертым этапом выполнялась имплантация петлевого

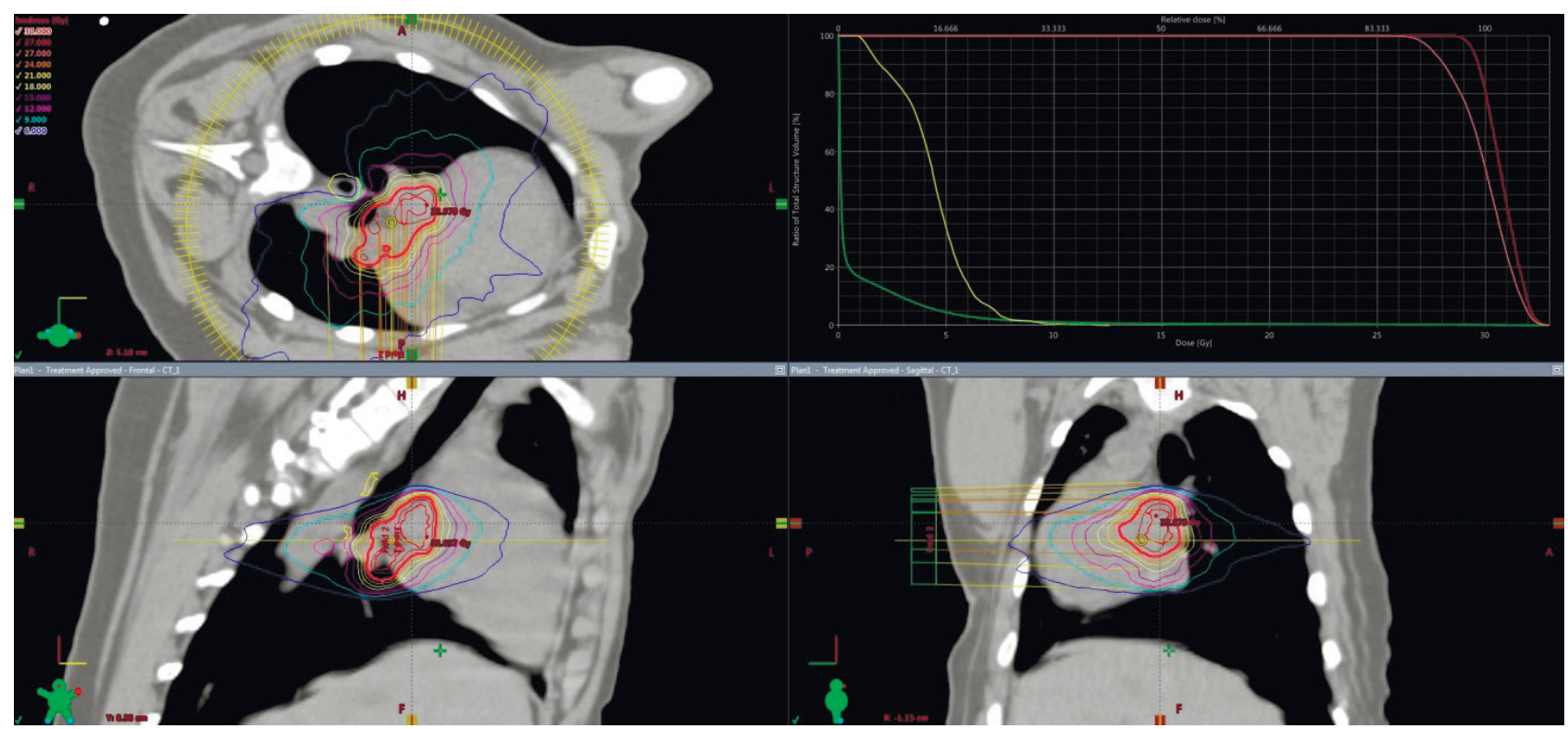

Рис. 1. Планирование облучения. Оконтуривание зоны предполагаемого воздействия (легочные вены). Представлены серии томограмм сердца свиньи в 3-х проекциях. Пицевод отмечен желтым контуром. На графике зависимости объема тканей от дозы, которую они получают, отмечено, что весь объем «мишени» (кривая красного цвета) облучается заданной высокой дозой, а пищевод (кривая жселтого цвета) "охлаждается", лучевая нагрузка минимизирована ("dose fall-off»). 
кардиомонитора Reveal (Medtronic, США) с возможностью удаленного мониторинга в правую боковую область грудной клетки животного с целью оценки ритма в течение всего периода эксперимента (передача показаний один раз в 14 суток) (параметры программирования Reveal: активации записи - пауза ритма более 1500 мс, детекция ФП/ТП, ЖТ менее 300 мс). Все работы с лабораторными животными были выполнены в соответствии с общепринятыми нормами обращения с животными на основе стандартных операционных процедур, соответствующих правилам Европейской Конвенции ETS, условия содержания животных соответствовали требованиям ГОСТ ИСО 10993-2.

Среднее время облучения составило $11 \pm 7$ минут. Интраоперационных осложнений не отмечалось. Планируемый срок отдаленного наблюдения составлял 6 месяцев с последующим проведением морфологического исследования аутопсийного материала. Извлеченные органокомплексы каждого животного оценивали макроскопически и фотографировали, фиксировали в $10 \%$ забуференном формалине $(\mathrm{pH} 7,0-7,2)$ в течение 48 часов после поперечных надрезов через 1,5 см.

На исследование забирались участки из органов «мишеней» (полнослойные участки сердца, включавшие в себя перикард, миокард и эндокард, с проводящей системой сердца, включая АВ-узел и коронарные артерии и вены сердца) и участки окружающих органов и тканей (легкие, пищевод, бронхи, перибронхиальные лимфатические узлы) (всего 167 образцов). Полученные образцы были помещены в гистологические кассеты и дополнительно фиксированы 10\% забуференным формалином ( $\mathrm{pH} 7,0-7,2)$ в течение 24 часов, промывались водой и обезвоживались в спиртах восходящей концентрации, далее заливались в парафиновые блоки по стандартному протоколу. Гистологические срезы толщиной 3 мкм готовили на автоматическом роторном микротоме HM 355 S (Thermo Scientific, Германия), расправляли на предметных стеклах (Gerhard Menzel GmbH, Германия). Cpeзы толщиной 3 мкм окрашивали гематоксилином и эозином в качестве обзорного метода. В качестве дополнительных методов исследования были проведены следующие гистохимические окраски: трихромом по Массону для выявления коллагеновых волокон I-IV типов, пикрофусином по ван Гизону для выявления коллагеновых волокон I-IV типов; ШИК-йодной кислотой (P.A.S.) для выявления гликополисахаридов в клетках проводящей системы сердца.

Основными задачами исследования являлись оценка конформности и гомогенности воздействия, а также анализ электрофизиологического эффекта после стереотаксической радиоаблации.

\section{ПОЛУЧЕННЫЕ РЕЗУЛЬТАТЫ}

Средний период наблюдения после эксперимен-

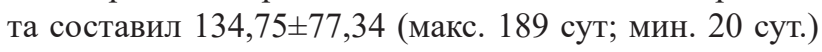
суток. Животные №1, 2, 3 прошли весь период наблюдения (6 мес).

Группа воздействия на АВ-узел. При макроскопическом исследовании во всех случаях в области АВ-узла отмечались заметные изменения в области воздействия, имеющие четкие, но не ровные границы зоны повреждения, не выходящие за пределы запланированных. Зона воздействия в системе планирования полностью совпадала с зоной воздействия на макропрепарате, т.е. воздействие было прецизионным (рис. $2 \mathrm{a}, б)$. Конформность облучения была достигнута при радиоаблации АВ-узла у всех животных (животные №1, 2, 4).

При микроскопическом исследовании отмечались изменения во всех слоях зоны локализации АВ-узла, представленные преимущественно зрелой грануляционной тканью среди неизмененных волокон миокарда, окрашивающейся пикрофуксином по ван Гизону в ярко-красный цвет и трихромом по Массону в синий (рис. 2в,г,д). В препаратах АВ-узла часть кардиомицитов была с полными (истинными) поперечными надрывами, явлениями коагуляции и вакуолизации цитоплазмы, характерных для острой стрессорной реакции. При этом степень гистологических изменений была наиболее выражена при максимальной нагрузочной дозе 45 Гр. В этих же зонах отмечалось наличие единичных сохранных кардиомиоцитов, принадлежащих проводящей системе.
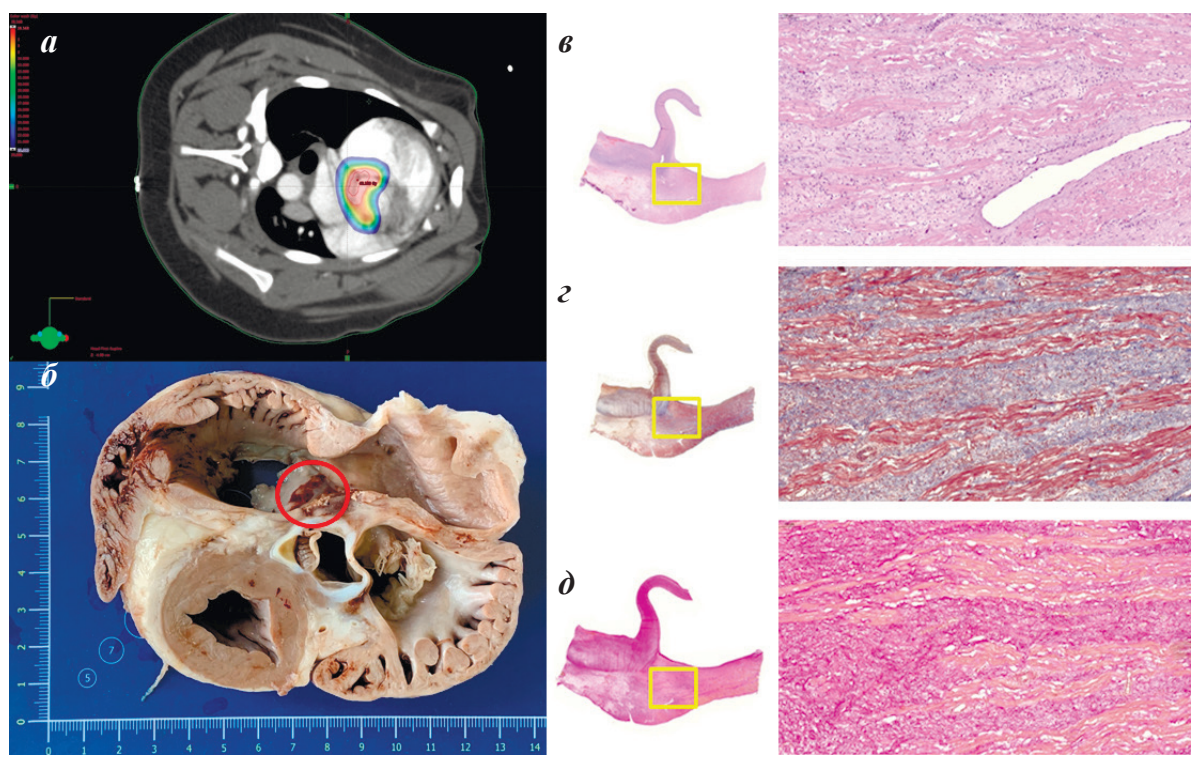

Рис. 2. Дозовое распределение в «мишени» (атриовентрикулярный узел) и прилегающих тканях на серии компьютерных томограмм сердца свиньи с контрастным усилением в аксиальной проекции в системе планирования лечения (а). Макропрепарат сердца свиньи, красной окружностью отмечена зона повреждения радиоаблации (б). Микропрепарат (увеличение 40-200) с окраской гемотоксилином-эозином (в), трихромом по Массону (2) и пикрофуксином по ван Гизону (д) области атриовентрикулярного узла после выполнения радиоаблации. Объяснение в тексте. 
По данным петлевого регистратора АВ - блокада 3 степени выявлена у животных №2 и №4. У животного №1 за весь период наблюдения нарушений ритма и проводимости не зарегистрировано. У животного № 2 AВ - блокада 3 степени имела преходящий характер преимущественно в ночные часы: минимальное ЧСС 16 уд. в мин, паузы ритма более 2 секунд, в количестве 1868 эпизодов за весь период наблюдения - 173 суток, максимальная продолжительность, продолжающееся АВ - блокады 3 степени - 42 минуты, блокада впервые выявлена на 108 сутки от имплантации регистратора (рис. 3). Животное № 4 погибло на 21 сутки эксперимента от асистолии вследствие развития полной АВ-блокады.

\section{Воздействие на устья легочных вен}

При макроскопическом исследовании препарата ЛП и ЛВ отмечается наличие измененных участков миокарда в области устьев ЛВ в виде геморрагического пропитывания и участков кальциноза. Зона воздействия в системе планирования полностью совпадала с зоной воздействия на макропрепарате, что говорит о высокой степени конформности воздействия.

При гистологическом исследовании участка, взятого из устьев ЛВ и в толще стенки ЛП в зоне проведенного воздействия отмечаются очаги кальциноза, отек и рыхлая соединительная ткань. Строма миокарда в указанных зонах с очаговым отёком. При исследовании прилежащих к зоне воздействия органов (легкие,
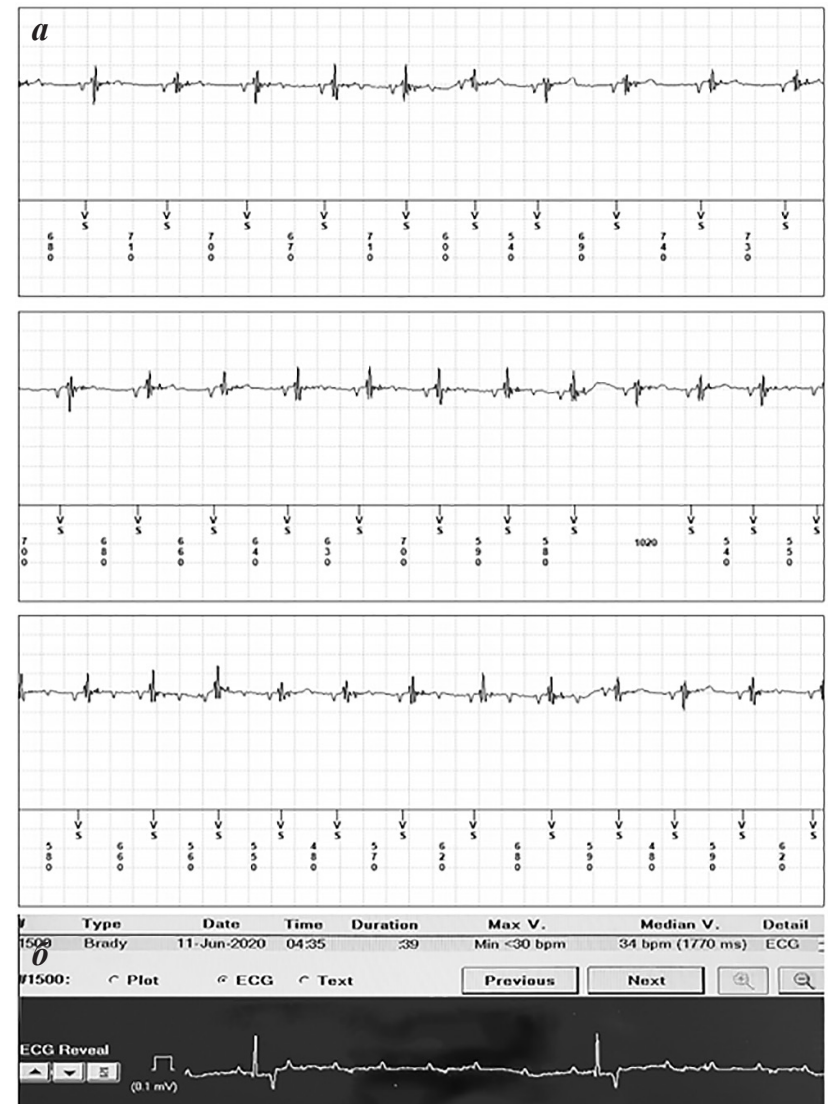

Рис. 3. Электрокардиограммы с петлевого кардиомонитора Reveal: a) в 1 день эксперимента (ритм синусовый, с частотой 100 уд/мин); б) на 108 сутки (зарегистрирован эпизод преходящей полной поперечной атриовентрикулярной блокады с частотой желудочковых сокращений менее 30 уд/мин. пищевод, бифуркационные лимфатические узлы) очагов некроза и фиброза не выявлено (рис. 4). За все время наблюдения у животного № 3 (устья ЛВ) нарушений ритма и проводимости не зафиксировано.

\section{Группа воздействий в левом желудочке}

При макроскопическом исследовании зона воздействия имеет четкие границы, которые почти полностью совпадают с планируемым объемом воздействия до процедуры (животное № 2 - верхушка ЛЖ и часть межжелудочковой перегородки, животное №4 - свободная стенка ЛЖ) (рис. 5).

При гистологическом исследовании миокарда верхушки ЛЖ с межпредсердной перегородкой (животное № 3) отмечается трансмуральный характер изменений: массивные поля фиброзной ткани различной степени зрелости (с преобладанием субэпикардиального) с очаговыми кровоизлияниями различной давности и грануляциями, окруженными кардиомиоцитами с коагуляцией и вакуолизацией цитоплазмы. У животного № 4 обращало на себя внимание наличие грануляций, очагов некроза, трансмурального фиброза (и очагов кальциноза, кровоизлияния в зоне воздействия) на всем протяжении воздействия (рис. 5). При этом передняя межжелудочковая артерия, частично проходя через зоны запланированного воздействия у обоих животных, не имела признаков повреждения и не была тромбирована, однако в субэндотелиальной зоне отмечались явления отека, частичной деструкции покровной пластинки, что косвенно может указывать на возможность пристеночного тромбообразования в отдалённые сроки (рис. 5).

В группе воздействия на ЛЖ у животных №2 и №4 по данным петлевого кардиомонитора желудочковых нарушений ритма зафиксировано не было. Животное №4 погибло от асистолии на фоне полной АВ-блокады на 21 сутки наблюдения.

Таким образом, согласно анализу макроскопических препаратов сердец, выполненные воздействия оказались прецизионными с высокой степенью конформности.

По данным микроскопического исследования, воздействия оказались трансмуральными, в данных зонах отмечались явления некроза и кальциноза, что говорит о гомогенном повреждении участков миокарда с последующим формированием фиброза.

Согласно, зарегистрированным с помощью петлевого кардиомонитора данным, выявлено, что воздействие на АВ-узел дозой, равной 35 Гр, не приводит к развитию стойкого электрофизиологического эффекта. Применение больших доз (40 и 45 Гр) продемонстрировало эффект в виде развития АВ-блокад различной степени тяжести.

\section{ОБСУЖДЕНИЕ ПОЛУЧЕННЫХ РЕЗУЛЬТАТОВ}

Одним из первых экспериментальных исследований по применению радиохирургии для решения задач аритмологии стала работа A.Sharma et al (2010). Исследование было проведено на 16 животных (мини-пиги) с использованием роботической стереотаксической системы для радиохирургии CyberKnife 
(Accuray Inc..., США.) Воздействия выполнялись в кава-трикуспидальном истмусе, АВ-узле, свободной стенке ЛЖ, ЛВ и ушке ЛП с нагрузочными дозами от 25 Гр до 80 Гр. Электрофизиологический контроль осуществлялся при проведении эндоэлектрофизиологического исследования с использованием системы навигационного картирования CARTO (Biosense Webster, США) до и после процедуры в период отдаленного наблюдения, в группе радиовоздействия на АВ-узел двум животным был имплантирован постоянный электрокардиостимулятор (ПЭКС). Срок отдаленного наблюдения составил 6 месяцев. Для создания двунаправленного блока проведения через кава-трикуспидальный истмус наиболее эффективной была доза 40 Гр с развитием эффекта через месяц после воздействия, в группе воздействия в ЛВ и ушка ЛП эффективными (уменьшение спайковой активности менее 0,05 мВ в ЛВ по данным ЭФИ) были дозы от 38 Гр и выше с развитием эффекта на 35 сутки. АВ-блокада развилась в одном случае с нагрузочной дозой при воздействии 70 Гр на 49 сутки наблюдения (одно из двух животных выбыло из исследования по причине нагноения ложа ПЭКС).

Повреждений окружающих сердце органов не отмечалось. Точный механизм повреждения тканей и клеток, по мнению авторов, не определен, но связан явлением апоптоза и протекающими иммунно-воспалительными процессами. При гистологическом исследовании отмечаются явления вакуолизации, эозинофильной инфильтрации, васкулита, ишемического повреждения с развитием фиброза и последующей кальцификации субстрата воздействия. Отсутствие термического компонента повреждения, по мнению авторов, определяет сохранение эндотелия сосудов и, как следствие, отсутствие признаков тромбоза капиллярного и артериального русла [11].

В нашем исследовании был достигнут функциональный эффект раньше и при применении меньшей нагрузочной дозы (преходящая АВ-блокада была достигнута при 40 Гр на 108 сутки наблюдения, при применении дозы 45 Гр животное скончалось от асистолии на 21 на фоне АВ-блокады 3 ст.). При гистологическом исследовании отмечены сходные изменения в зонах воздействия.

В исследовании M.Refaat et al (2017), выполненном на свиньях, для оценки эффективности стереотаксического метода лечения аритмии была произведена аблация АВ-узла с целью оценки электрофизиологического эффекта с различными нагрузочными дозами (35 Гр и двум - 40 Гр). Контроль возникновения АВ-блокады осуществлялся
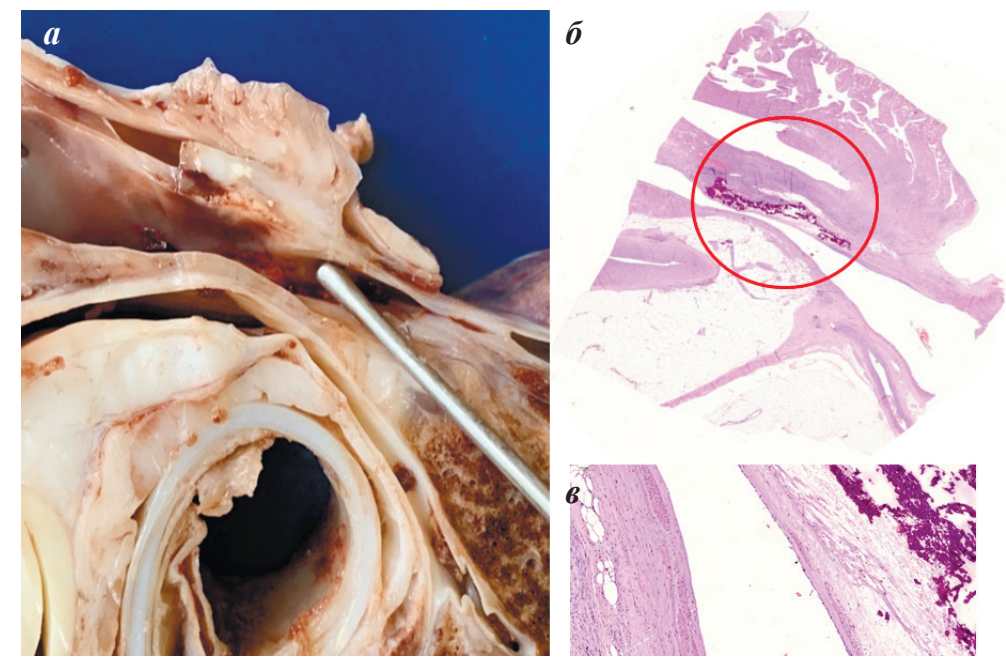

Рис. 4. Макропрепарат фрагмента устья легочной вены сердца свиньи после радиоаблации (а); микропрепарат данного участка, окраска гематоксилин-эозин, увеличение 40 (б); фрагмент микропрепарата, отмеченный красной окружностью, с захватом зоны воздействия, увеличение 200 (в).
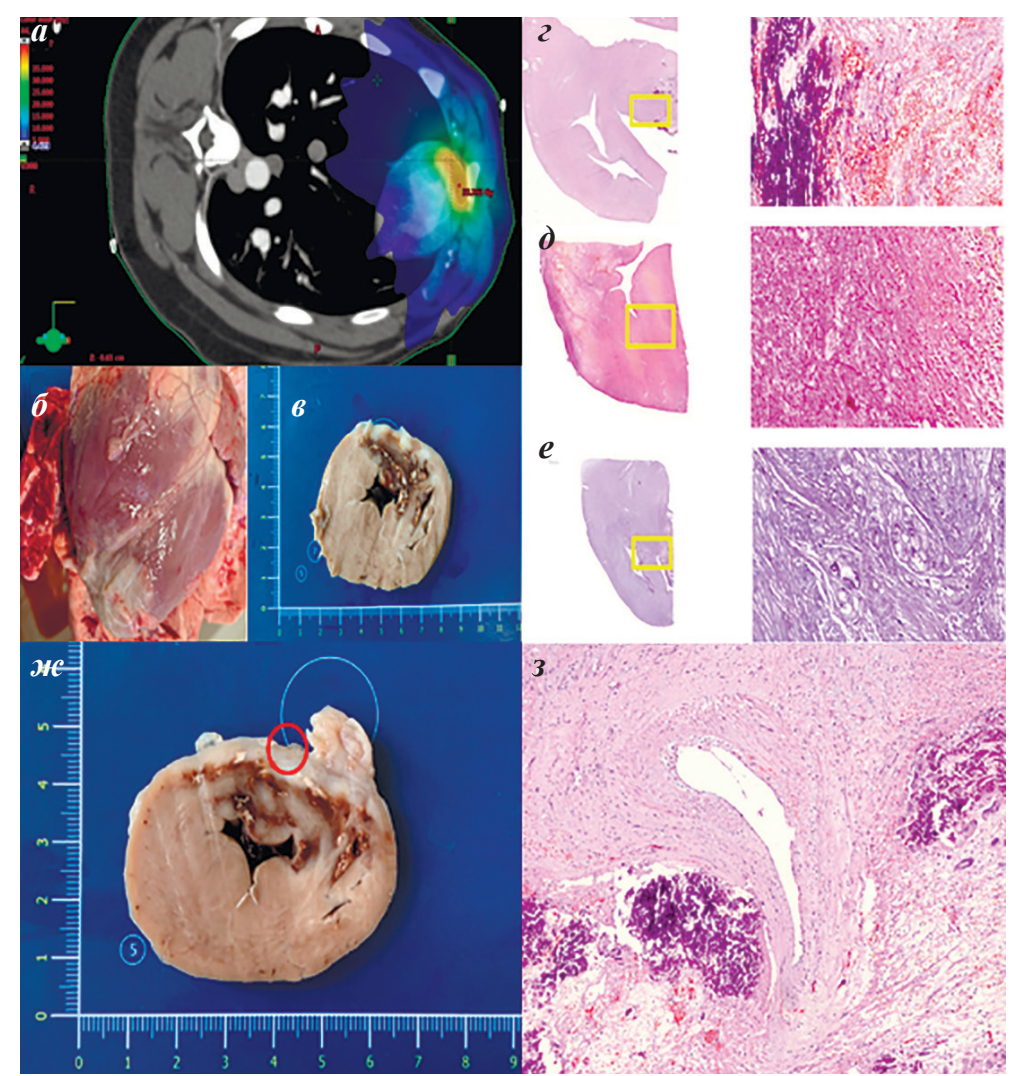

Рис. 5. Компьютерный томографический срез с контрастным усилением зоны верхушки левого желудочка свиньи в системе планирования лечения (а); макропрепарат сердца свиньи, в области верхуики отмечается зона фиброза (б); макроскопический срез сердца свиньи после радиоаблации, измененная зона соответствует зоне воздействия (в). Микропрепарат фрагмента верхуики левого желудочка после радиоаблации (увеличение 40-200): окраска гематоксилином-эозином (2), пикрофуксином по ван Гизону (д), ШИК-йодной кислотой (е). Макропрепарат левого жселудочка свиньи после радиоаблации, красной окружностью обозначена проекция передней межжелудочковой ветви (ж); микроскопический срез стенки левого желудочка на уровне передней межжелудочковой ветви, окраска гематоксилиномэозином, увеличение 200 (3). Объяснение в тексте. 
при помощи ранее имплантированного ПЭКС. В среднем АВ-блокада развивалась в течение 2 месяцев. На аутопсии для гистологического исследования были взяты материалы из АВ-узла и смежных органов. В препаратах АВ-узла наблюдались явления нарушения архитектоники ткани и дезорганизации внутриклеточных структур, а также некрозы и отложения фибрина. При гистологическом исследовании в препаратах печени, легких, пищевода патологических изменений найдено не было [12].

Группой профессора Paul C. Zei et al (2018) проведено исследование возможности выполнения стереотаксической радиоаблации устьев ЛВ (нагрузочные дозы 15-35 Гр). Эксперимент выполнен на собаках и свиньях с последующим отдаленным наблюдением. До и после проведения стереотаксического облучения проводилось электрофизиологическое исследование с использованием электроанатомического картирования зон спайковой активности в устьях ЛВ САRTO (Bioscence Webster, США). Контрольное электроанатомическое картирование проводилось на третий и шестой месяц наблюдения. Эффективность изоляции ЛВ составила $100 \%$ в группах с дозой воздействия 25 и 35 Гр, 80\% - в группе 20 Гр, оказалась неэффективна в группе 15 Гр [13].

В двух аналогичных нашей по дизайну статьях группы авторов из Германии и США, выполненных на одной группе животных (свиньи $\mathrm{n}=17$ ) и использовавших в качестве источника энергии линейный углеродный ускоритель (carbon beam), описываются схожие эффекты. Так, в первой публикации исследования I.Lehmann et al (2016), включавшем 17 животных (свиней), которые были разделены на 4 группы по зонам воздействия: группа воздействия на $\mathrm{AB}-\mathrm{yзел}(\mathrm{n}=8$, целевые дозы 25-55 Гр), правую верхнюю легочную вену (n=3, целевые дозы 30-40 Гр), свободную стенку левого желудочка сердца $(\mathrm{n}=3$, целевая доза 40 Гр), контрольную группу $(\mathrm{n}=3)$. Исследование проводилось с использованием углеродного линейного ускорителя в исследовательском центре лучевой терапии (Хей- дельберг, Германия). Средний срок наблюдения составил 20,3 недель. Отдаленные результаты оценивались при проведении позитронно-эмиссионной томографии и электрофизиологического исследования (1, 3 и 6 месяцев), аутопсии. В группе АВ-блокады эффект достигнут при дозах 40 и 55 Гр в двух случаях из 6 , при этом АВ-блокада при воздействии на узел дозой 40 Гр была обратима (зафиксирована на сроке 3 месяев, при исследовании на сроке 6 месяцев АВ-блокада не зарегистрирована), у трех животных развилась инфекция ложа ПЭКС и они выбыли из исследования. Также такие результаты авторы объясняют сложностью при оконтуривании «мишени» (АВ-узла). При воздействиях в ЛВ отмечалось снижение спайковой активности, в том числе, и в остром периоде при всех использованных дозах. При воздействии на свободную стенку ЛЖ точность воздействия оценивали с помощью позитронно-эмиссионной томографии и полученного аутопсийного материала. Обнаруженные изменения в ЛЖ по объему и площади находились в соответствии с планом облучения [14].

Во второй работе данного коллектива авторов основное внимание уделяется патогистологии и патоморфологии лучевого повреждения. Так, при гистологическом и иммуногистохимическом исследовании аутопсийного материала не наблюдалось повреждений тканей пищевода, трахеи и диафрагмального нерва, а также кожи, что свидетельствует о прецизионности и селективности проведенного облучения. Коронарные артерии, проходящие в зоне воздействия, также не были повреждены и тромбированы. Также отмечалось геморрагическое пропитывание миокарда зоны воздействия с миграцией макрофагов и сидеробластов в зону воздействия, положительно коррелирующее c величиной полученной нагрузочной дозы воздействия. Воспалительные повреждения миокарда зоны воздействия оценивались по наличию активированных T-клеток (маркер CD 45+) и также были более выражены в группах с высокими дозами облучения и в зонах максимального видимого повреждения миокарда, что

Характеристика зон воздействия

Таблица 1.

\begin{tabular}{|c|c|c|c|c|c|c|}
\hline & №1 & \multicolumn{2}{|c|}{ №2 } & №3 & \multicolumn{2}{|c|}{ №4 } \\
\hline Дата эксперимента & 7.12.2019 & \multicolumn{2}{|c|}{ 21.12.2019 } & 18.01 .2020 & \multicolumn{2}{|c|}{1.02 .2020} \\
\hline Пол & муж & \multicolumn{2}{|c|}{ жен } & муж & \multicolumn{2}{|c|}{ жен } \\
\hline Зона воздействия & АВ-узел & АВ-узел & ВЛЖ & ЛВ & АВ-узел & ССЛЖ \\
\hline Нагрузочная доза, Гр & 35 & 40 & 35 & 30 & 45 & 40 \\
\hline Объем GTV, куб. см & 2,4 & 3,7 & 2,4 & 5,6 & 7,9 & 1,9 \\
\hline Отступ GTV-PTV (мм) & 3 & 3 & 3 & 3 & $2-3$ & 5 \\
\hline Объем PTV, куб. см. & 7,9 & 9,6 & 7,5 & 15,2 & 20,9 & 13 \\
\hline Энергия пучка, Мэв & $6 x$ & \multicolumn{2}{|c|}{$6 \mathrm{x}-\mathrm{FFF}$} & $6 \mathrm{x}-\mathrm{FFF}$ & \multicolumn{2}{|c|}{$6 \mathrm{x}-\mathrm{FFF}$} \\
\hline Мощность пучка, ме/мин & 600 & \multicolumn{2}{|c|}{1400} & 1400 & \multicolumn{2}{|c|}{1400} \\
\hline Время воздествия & 23 мин 44 с & \multicolumn{2}{|c|}{8 мин 20 с } & 6 мин 16 с & \multicolumn{2}{|c|}{9 мин 38 с } \\
\hline
\end{tabular}

Примечание: АВ - атриовентрикулярный, ЛВ - легочные вены, ВЛЖ и ССЛЖ - верхушка и свободная стенка левого желудочка, GTV (Gross Target Volume) - объем выделенной зоны интереса, PTV (Planning Target Volume) объем зоны интереса с учетом отступа, FFF (Flattening Filter-Free) - режим работы линейного ускорителя без выравнивающего фильтра. 
было также характерно и для выраженности явлений фиброза (степень депонирования коллагена) и миоцитолиза [15].

Применение данной технологии для лечения тахиаритмий определенно имеет высокие перспективы в современной аритмологии в качестве альтернативного метода аблации у пациентов с неэффективным катетерным подходом, а также у пациентов, имеющих противопоказания к проведению интервенционных процедур. Дальнейшее развитие этой технологии в аритмологии определенно требует проведения как экспериментальных, так и расширенных клинических исследований для определения уровня эффективности и безопасности метода. Открытыми остаются ряд сложных вопросов и задач, таких как определение необходимой величины терапевтической дозы для создания функционального и гомогенного повреждения миокарда при различных локализациях воздействия; обеспечение точности воздействия с учетом непрерывного движения структур и органов в грудной полости; возможная обратимость созданного повреждения миокарда; возможная «проаритмогенность», выполняемых воздействий; перспектива создания «истинного (патогенетического) антиаритмического» воздействия, что является предметом дальнейших исследований.

\section{ОГРАНИЧЕНИЯ ИССЛЕДОВАНИЯ}

Ограничениями проведенного нами исследования являлись: небольшое количество животных, включенных в исследование, существенное отличие анатомии сердца и расположения прилежащих органов от сердца человека, хотя сердце свиньи является общепринятой моделью для экспериментальных исследовании в области кардиохирургии и аритмологии, и то, что ионизирующее излучение может иметь долгосрочные побочные эффекты, которые необходимо оценить для этой технологии при моделировании риска и пользы в долгосрочных экспериментальных исследованиях. Не были использованы максимальные нагрузочные дозы для воздействия (50 Гр и выше). В связи с имплантаци- ей петлевого регистратора непосредственно после вмешательства, не представлялось возможным задокументировать отсутствие или наличие нарушений ритма у животных до проведения вмешательства. Также в нашем исследовании мы могли оценить только посмертный аутопсийный материал, и не могли функционально в среднесрочном и отдаленном периоде проверить состоятельность радиоаблации в ЛВ и желудочках сердца при использовании электрофизиологического контроля, что станет целью при продолжении нашего экспериментального исследования.

\section{ЗАКЛЮЧЕНИЕ}

Согласно результатам проведенной работы в данном экспериментальном исследовании в каждой группе воздействия повреждения оказывались прецизионными и безопасными. При гистологическом анализе образцов сердец выявлено, что устойчивое морфологическое повреждение было достигнуто при всех примененных дозах облучения. Мы достигли функционального повреждения миокарда в области АВ-соединения как преходящей полной АВ-блокады (при дозе 40 Гр на 108 сутки наблюдения), так и постоянной АВ-блокады 3 ст. (45 Гр на 21 сутки) с использованием пучка фотонов мощностью 6 МэВ. Тем не менее, доза 35 Гр не оказалась достаточной для развития электрофизиологических изменений при воздействии на АВ-узел. Объемы лучевого поражения тканей сердца, анализируемые при аутопсии, положительно коррелировали с распределением дозы вокруг целевого объема повреждения, т.е. воздействия, были в высокой степени конформны (совпадали по объему) и прецизионны.

Проведенные экспериментальные исследования доказывают, что использование стереотаксической радиоаблации демонстрирует достаточно высокие показатели эффективности и безопасности методики для создания стойкого повреждения миокарда у экспериментальных животных, основные положения исследований, проведенных за рубежом, были воспроизведены в нашем эксперименте.

\section{ЛИТЕРАТУРА}

1. Васковский ВА. Ближайшие и отдаленные результаты радиочастотной модификации операции «Лабиринт» на работающем сердце у пациентов с пароксизмальной и персистирующей формой фибрилляции предсердий/ дис. кандидата медицинских наук // Науч. центр сердечно-сосудистой хирургии им. А.Н. Бакулева РАМН. Москва, 2016:43 [Vaskovskiy VA Immediate and long-term results of radiofrequency modification of the operation "Maze" on a beating heart in patients with paroxysmal and persistent atrial fibrillation. Dis. candidate of medical sciences. Scientific center of cardiovascular surgery named after A.N. Bakuleva RAMN. Moscow, 2016: 43(In Russ.)].

2. Кушаковский МС. Аритмии сердца: Руководство для врачей. - 3-е изд., испр. и доп. - СПб.: Фолиант, 2004: с 672. [ Kushakovsky MS. Cardiac Arrhythmias: A Guide for Physicians. - 3rd ed., Rev. and add. - SPb .: Foliant, 2004: p 672 (In Russ).] ISBN: 978-5-93929-083-8.

3. Schron EB, Exner DV, Yao Q, et al. Quality of life in the antiarrhythmics versus implantable defibrillators trial: impact of therapy and influence of adverse symptoms and defibrillator shocks. Circulation. 2002;105: 589-594. DOI:10.1161/hc0502.103330.

4. Ревишвили АШ. Неинвазивная диагностика и аблация аритмий - миф или реальность? Вестник аритмологии. 2020; 27(3): 5-8 [Revishvili A.S. Noninvasive arrhythmia mapping and ablation - myth or reality? Journal of Arrhythmology. 2020;27(3): 5-8. (In Russ.)] DOI: org/10.35336/VA-2020-3-5-8.

5. Brueggemann B, Eitel I, Heeger C, et al. Preventive Ventricular Tachycardia Ablation in Patients with Ischaemic Cardiomyopathy: Meta-analysis of Randomised Trials. Arrhythm Electrophysiol. 2019;8(3): 173-179. DOI:10.15420/aer.2019.31.3.

6. Cappato R, Calkins H, Chen SA, et al. Worldwide survey on the methods, efficacy, and safety of catheter ablation for human atrial fibrillation. Circulation. 2005.8;111(9): 11005 DOI:10.1161/01.CIR.0000157153.30978.67. 
7. Голанов АВ. Стереотаксическое облучение патологии ЦНС на аппарате КиберНож. Монография - ИП Т.А.Алексеева Москва 2017;32 [Golanov A. V. Stereotactic irradiation of CNS pathology using the CyberKnife. Monograph. Moscow 2017:32 (In Russ.)] ISBN: 978-5905221-3.

8. Таймасова ИА, Васковский ВА, Артюхина ЕА, и др. Возможности и перспективы применения стереотаксической радиохирургии для проведения неинвазивных вмешательств в аритмологии. Вестник аритмологии. 2020;4(102): 19-27. [Taymasova IA, Vaskovskiy VA, Artyukhina EA, et al. Opportunities and perspectives of stereotactic radiosurgery for non-invasive arrhythmology interventions. Journal of Arrhythmology. 2020; 4 (102): 19-27 ] DOI: org/10.35336/VA-2020-4.

9. Neuwirth R, Cvek J, Knybel L, et al. Stereotactic radiosurgery for ablation of ventricular tachycardia. Europace. 2019;21(7): 1088-1095.

10. Lloyd MS, Wight J, Schneider J, et al. Clinical experience of stereotactic body radiation for refractory ventricular tachycardia in advanced heart failure patients. Heart Rhythm. 2020;17(3): 415-422.
11. Sharma A, Wong D, Weidlich G, et al. Noninvasive stereotactic radiosurgery (CyberHeart) for creation of ablation lesions in the atrium. Heart Rhythm. 2010:7(6): 802810. DOI: $12.1016 /$ j.hrthm.2010.02.010.

12. Refaat M, Ballout JA, Zakka P, et al. Swine Atrioventricular Node Ablation Using Stereotactic Radiosurgery: Methods and In Vivo Feasibility Investigation for Catheter-Free Ablation of Cardiac Arrhythmias. $J$ Am Heart Assoc. 2017;6(11): e007193 DOI: 10.1161/ JAHA.117.007193.

13. Zei PC, Wong D, Gardner E, et al. Safety and Efficacy of Stereotactic Radioablation Targeting Pulmonary Vein Tissues in an Experimental Model. Heart Rhythm. 2018;15(9): 1420-1427. DOI: 10.1016/j.hrthm.2018.04.015.

14. Lehmann I, Graeff C, Simoniello P, et al. Feasibility Study on Cardiac Arrhythmia Ablation Using High-Energy Heavy Ion Beams. Sci Rep. 2016; 6:388-95 DOI: 10.1038/ srep38895.

15. Rapp F, Simoniello P, Wiedemann J, et al. Biological Cardiac Tissue Effects of High-Energy Heavy Ions - Investigation for Myocardial Ablation. Sci Rep. 2019;9(1):5000. DOI: $10.1038 /$ s41598-019-41314-X. 